\title{
Setting-up of natural delivery centers; an affordable policy to improve the quality of maternity care
}

Javad Aghazadeh-Attari

Urmia University of Medical Sciences

Cyrus Alinia ( $\nabla$ siros_alinia@yahoo.com )

Urmia University of Medical Sciences https://orcid.org/0000-0002-5387-3134

Rasool Entezar-Mahdi

Urmia University of Medical Sciences

Mohammad Mirza-Aghazadeh-Attari

Tabriz University of Medical Sciences

Iraj Mohebbi

Urmia University of Medical Sciences

Research article

Keywords: quality of care, midwife, normal vaginal delivery, gynecologist

Posted Date: December 2nd, 2019

DOI: https://doi.org/10.21203/rs.2.17866/v1

License: (c) (i) This work is licensed under a Creative Commons Attribution 4.0 International License.

Read Full License 


\section{Abstract}

Background: Since there is no comprehensive model to measure the quality of maternity care and also health systems are facing the challenge of increasing the cost of such care, We developed a quality of maternity care model, measured the quality of care in a normal delivery center (NDC) compared to a mixed delivery center (MDC). It also compared the performance of midwives against gynecologists for uncomplicated pregnant mothers.

Methods: A theory-based maternity care model is used to compare the quality of maternity care for the delivery centers. This model consists of three dimensions of the structure, process, and output. Mothers who have given birth in the delivery centers were the primary data source in Urmia city, Iran in 2018. A total of 164 mothers from the NDC and 215 mothers from MDC were randomly selected and interviewed.

Results: The mean age of mothers in the NDC and MDC was 24.7 and 27.1 years, respectively. The findings show that NDC significantly had better performance compared to MDC in all three dimensions. However, we observed significant differences in some outcome variables (the experience of pain and follow-up) in favor of MDC.

Conclusions: Midwives in NCD provide a higher quality of care than gynecologists in general hospital. The policy of setting up natural childbirth centers run by trained midwives can have positive effects, such as decreasing cesarean rates and cost of care and also increasing the quality of childbirth care.

\section{Background}

Between 1990 and 2015, maternal mortality worldwide dropped by about 44\%.[1] Nevertheless, there are about 340,000 deaths per year,[2] 99\% of them happened in developing countries.[3] According to the goals set by the United Nations for Sustainable Development Goals (SDGs), maternal mortality rates need to be 70 maternal deaths per 100,000 live births and infant mortality rates should be 12 per 1,000 live births. Due to poor access to maternal and childcare, including specialized staffing, diagnostic and therapeutic facilities, and medications,[4, 5] low- and middle-income countries are far behind this target. [6]

In general, maternal, stillbirths, and neonatal mortalities are associated with poor quality of care before, during, and after delivery.[7] Undoubtedly, trained and experienced human resources can provide quality care services to pregnant women and their newborns.[8] In health systems, gynecologists and midwives are responsible for the tasks mentioned above, and in uncomplicated cases, midwives can replace gynecologists.[9]

Safe Motherhood Initiative, which was presented at an international conference in Nairobi, Kenya, was the first targeted and successful activity to improve the quality of maternity care to control the gloomy maternal mortality rate throughout the world, especially economically emerging countries. The initiative has highlighted the need to improve the status of women, community education, and maternal health 
(antenatal care, delivery care, and postpartum care).[10] Although the initiative achieved relative success in all countries, after 2000 few native and national initiatives such as Emergency Obstetric and Neonatal Care and Maternity Waiting Homes were developed in African countries which still experienced high mortality rates such as South Africa, Ethiopia, Zimbabwe, Malawi, Zambia, and Uganda.[11, 12]

The obstetric birth model in Iran is the dominant maternal care approach due to the fee-for-service payment system, lack of clear clinical guidelines, and absence of performance transparency at organizational levels.[13] Because of the dominance of gynecologists in both policy-making and implementation of women's health care, there is an apparent conflict of interest that has led to the overlooked role of midwives in maternal care. This challenge could potentially increase the cost of receiving needed care, increase the share of cesarean delivery, and reduce access to midwives' public services. $[14,15]$ Recently, in order to improve access to childbirth care services, the Iranian health system established a natural delivery center (NDC) on the outskirt of Urmia city in 2017, which manages uncomplicated pregnancy by midwives, and assigns medium-to-high risk cases to gynecologists, precisely like the mechanism that is running in the Netherlands.[16] Of course, this action was used to control the increasing rate of cesarean delivery in Urmia, which is now higher than $40 \%[17]$ and considerably more than the global rate of cesarean section (10-15\%) recommended by the World Health Organization.[18] Cesarean section can cause complications for the mother and the newborn,[19] Although because of the nature of high-risk cases undergoing Cesarean section an increased rate of mortality is expected, studies have reported a positive relationship between high rates of elective Cesarean section and higher maternal mortality rates, excluding the complicating factors seen in patients undergoing Cesarean section.[20, 21]

Nowadays, the expectations of mothers and their families about the experience of childbirth have gone far beyond, and they want a safe, comfortable, affordable, accessible, and high-quality delivery from the health system. Therefore, the concept of quality of delivery care includes structural and process factors in addition to delivery outcomes such as mortality, morbidity, and maternal satisfaction.[22] Wiegers in the Netherlands has attempted to model and study the quality of maternity care in the Netherlands. She used the Consumer Quality Index, which asked mothers about the actual experiences of childbirth from the structural and process aspects of the "delivery path". The results show the high quality of maternity care in all different settings throughout the care system, especially when they give birth at home, and they are their midwife assists them. This model is unable to comprehensively identify and measure attributes that determine the quality of childbirth care, as well as less emphasis on the outcomes.[16] In a study, Redshow et al., also introduced maternal satisfaction factor in different stages of labor, for different service providers, and in different settings as an indicator for measuring the quality of maternity care.[22]

This study aimed to compare the quality of care delivered by the NDC and mixed delivery center (MDC) using a comprehensive model based on the quality of maternity care assessment theory that was designed and presented by researchers in this study.

\section{Methods}


Design

A cross-sectional analytical study using primary data, which is achieved from the self-reported questionnaires in Urmia, Iran, in 2018. To assess the quality of maternity care for a safe and reliable delivery in the studied centers, a novel model of quality of care was developed and presented based on Donabedian's health care quality model. This model consists of three dimensions of the structure, process, and output, which is a client-centered approach.[23] The structure dimension consists of the privacy of the delivery room, time to get the center (access time to the maternal center from home), waiting time in delivery center, cleanness, and calmness of delivery room. The process dimension includes items such as husband's accompaniment, asking delivery type preferences (normal delivery and cesarean delivery), reliable and intimate relationship between the mother and the maternity care providers, providing care information to the mother, and the skill of maternal healthcare providers. Finally, the outcome dimension of the model deals with the amount of pain experienced (very low, low, moderate, severe, very severe), level of postpartum follow-up, satisfying health and non-therapeutic needs, answering mother's questions, fixing health concerns of mother and infant, the unintended side-effects for mother and baby and ultimately the mother's overall satisfaction with the provider team.

The study aimed to design a quality of maternity care model, compare the quality of care delivered by midwives and gynecologists, and also compare the quality of maternity care provided by the NDC and MDC.

\section{Participants}

We compared the mothers who gave birth in the NDC for six months before with their counterparts in the MDC. For this purpose, 164 and 215 mothers in the NDC and the MDC, respectively, were analyzed based on different dimensions of labor experience. To eliminate the possible biases regarding the comparison of the two heterogeneous groups, we made an additional comparison only among the 26 mothers who had experience of giving birth in both centers. All of these mothers had given previous birth in MDC and their last birth in the NDC. The MDC is located at a general Hospital, and the NDC is under the supervision of the Urmia Health Network. In the NDC, all non-complicated labor is performed vaginally with the consent of the pregnant mother, and complex cases are referred to gynecologists at the same facility. Nevertheless, in the MDC, which is a university hospital center, some non-complicated deliveries are performed as cesarean section, at the request of the mothers or to the doctor's diagnosis. Mothers did not have any severe or chronic illness, and they were not complicated cases for delivery. It means that all the mothers have completed their delivery in a normal condition. Using Excel software, the codes of participants were selected randomly from a list of all eligible mothers and recorded their birth certificate and contact information.

\section{Data collection}

The finalized items of the model were extracted and categorized by reviewing the literature on the quality of maternity care.[24-27] Base on, we designed a specific questionnaire in the Persian language with two 
main components: (a) demographic characteristics, and (b) dimensions of health care quality. The questionnaires were completed by three trained health workers in June 2018 through a telephone interview with the randomly selected mothers after the mothers announced their verbal consent to participate in the study.

\section{Data analysis}

We analyzed the data by STATA software Version 8.0 [StataCorp, Inc., 2003]. Independent t-test and oneway ANOVA were used to compare the mean of quantitative data, and the qualitative data were analyzed using Mann Whitney $U$ and Kruskal-Wallis. $P<0.05$ was considered significant.

Validity and reliability

The preliminary version of the questionnaire, which included questions to assess each of the criteria for measuring the quality of maternity care, was extracted from a review of related studies. We evaluated the questionnaire for finalization by seven maternal and child specialists, Obstetricians, and midwives. So the questionnaire seems to be highly validated. Reliability was measured using test-retest within a two-week interval among 25 of the studied mothers in both centers. Study reporting follows STROBE guidelines to enhance rigor and transparency.

\section{Results}

The response rate of the mothers in the NDC and MDC was 0.85 and 0.87 , respectively. Except for the place of residence, we observed no significant differences in other demographic characteristics of the mothers that gave birth in these centers. The percentage of urbanization in the mothers referred to NDC and MDC were $14 \%$ and $41 \%$, respectively. The mean age of mothers in the NDC and MDC was 24.7 and 27.1 years, respectively, and the household dimension of these two groups was 3.7 and 3.4, respectively. (Table 1) 
Table 1

Demographic characteristics of studied mothers in the NDC and MDC in Iran

\begin{tabular}{|c|c|c|c|}
\hline Characteristics & $\operatorname{NDC}(n=164)$ & $\operatorname{MDC}(n=215)$ & P-value \\
\hline Delivery age [Mean (SE)] & $24.7(3.5)$ & $27.1(5.6)$ & 0.73 \\
\hline Education years[Mean (SE)] & $9.52(3.67)$ & $10.3(4.11)$ & 0.89 \\
\hline Household dimension[Mean (SE)] & $3.7(0.8)$ & $3.4(0.7)$ & 0.78 \\
\hline Monthly expenditures [Mean (SE)] & $337.32(123.87)$ & $381.12(139.31)$ & 0.82 \\
\hline Having Job [Number (\%)] & $31(19)$ & $34(16)$ & 0.92 \\
\hline $\begin{array}{l}\text { Place of Residence [Number (\%)] } \\
\text { Urban } \\
\text { Suburban } \\
\text { Rural }\end{array}$ & $\begin{array}{l}23(14) \\
138(84) \\
3(2)\end{array}$ & $\begin{array}{l}88(41) \\
97(45) \\
30(14)\end{array}$ & $<0.01$ \\
\hline Having health insurance (\%) & $164(100)$ & $211(98)$ & 1 \\
\hline \multicolumn{4}{|l|}{ Abbreviations: } \\
\hline \multicolumn{4}{|c|}{ NDC Natural Delivery Center, MDC Mixed delivery center, SE standard error } \\
\hline \multicolumn{4}{|c|}{$\begin{array}{l}\text { Notes: NDC is a delivery center which only perform natural vaginal delivery for non-complicated } \\
\text { pregnancy. MDC is a delivery center which do both natural vaginal delivery and cesarean section, at } \\
\text { the request of the mothers or to the doctor's diagnosis. }\end{array}$} \\
\hline \multicolumn{4}{|c|}{$\begin{array}{l}\text { The results of the test-retest analysis showed that the reliability coefficients concerning three } \\
\text { dimensions of the structure, process, and output of the questionnaire were calculated as } 0.91,0.86 \text {, } \\
\text { and } 0.95 \text {, respectively. Findings on the quality of maternal care in the NDC and MDC indicate that } \\
\text { there were significant differences in all the dimensions (structure, process, and output). All the } \\
\text { mothers had private rooms in the NDC, while none of the mothers had such facilities in MDC. }\end{array}$} \\
\hline
\end{tabular}


Table 2

Quality of care from mother's perspective in the NDC and MDC in Iran (Model A)

\begin{tabular}{|c|c|c|c|c|c|c|}
\hline \multirow[t]{2}{*}{ Quality of care variables } & \multirow[t]{2}{*}{$\begin{array}{l}\text { Possible } \\
\text { ranges }\end{array}$} & \multicolumn{2}{|c|}{$\begin{array}{l}\text { NDC } \\
(n=164)\end{array}$} & \multicolumn{2}{|c|}{$\begin{array}{l}\text { MDC } \\
(n=215)\end{array}$} & \multirow[t]{2}{*}{$\begin{array}{l}\mathrm{P} \text { - } \\
\text { value }\end{array}$} \\
\hline & & Mean & SE & Mean & SE & \\
\hline \multicolumn{7}{|l|}{ Structure factors } \\
\hline Privacy of the delivery room & {$[0-100]$} & 100 & - & 0 & - & $<0.01$ \\
\hline Time to get the center (Minute) & {$[0-\infty)$} & 12.4 & 6.7 & 54.7 & 36.3 & 0.31 \\
\hline Waiting time (Minute) & {$[0-\infty)$} & 3.8 & 1.9 & 6.4 & 3.5 & 0.55 \\
\hline Cleanliness of delivery room & {$[1-5]$} & 4.94 & 0.94 & 3.23 & 0.19 & 0.04 \\
\hline Calmness of delivery room & {$[1-5]$} & 4.63 & 0.67 & 3.76 & 0.30 & 0.20 \\
\hline \multicolumn{7}{|l|}{ Process factors } \\
\hline Husband's Accompaniment & {$[0-100]$} & 73 & - & 14 & - & $<0.01$ \\
\hline $\begin{array}{l}\text { Taking into account mother's } \\
\text { preferences }\end{array}$ & {$[0-100]$} & 100 & - & 11 & - & $<0.01$ \\
\hline Reliable and intimate relationship & {$[1-5]$} & 4.72 & 0.88 & 3.99 & 0.62 & 0.48 \\
\hline Provide care information & {$[1-5]$} & 3.44 & 0.26 & 2.81 & 0.17 & 0.03 \\
\hline Meeting needs & {$[1-5]$} & 4.24 & 0.46 & 3.76 & 0.31 & 0.37 \\
\hline Answering questions & {$[1-5]$} & 4.54 & 0.67 & 3.16 & 0.18 & 0.03 \\
\hline Meeting concerns & {$[1-5]$} & 4.43 & 0.55 & 3.68 & 0.28 & 0.19 \\
\hline Provider skills & {$[1-5]$} & 4.21 & 0.42 & 4.11 & 0.41 & 0.87 \\
\hline \multicolumn{7}{|l|}{ Outcome factors } \\
\hline Pain & {$[1-5]$} & 4.74 & 0.75 & 2.07 & 0.17 & $<0.01$ \\
\hline Follow-up & {$[0-100]$} & 14 & - & 37 & - & $<0.01$ \\
\hline Maternal complications (\%) & {$[0-100]$} & 0 & - & 6 & - & $<0.01$ \\
\hline Newborn complication (\%) & {$[0-100]$} & 0 & - & 0 & - & 1 \\
\hline Mother's satisfaction & {$[1-5]$} & 4.70 & 0.73 & 3.53 & 0.31 & 0.11 \\
\hline \multicolumn{7}{|c|}{ Abbreviations: NDC Natural Delivery Center, MDC Mixed delivery center, SE standard error } \\
\hline
\end{tabular}




\begin{tabular}{|c|c|c|c|c|c|c|}
\hline \multirow[t]{2}{*}{ Quality of care variables } & \multirow[t]{2}{*}{$\begin{array}{l}\text { Possible } \\
\text { ranges }\end{array}$} & \multicolumn{2}{|c|}{$\begin{array}{l}\text { NDC } \\
(n=164)\end{array}$} & \multicolumn{2}{|c|}{$\begin{array}{l}\text { MDC } \\
(n=215)\end{array}$} & \multirow[t]{2}{*}{$\begin{array}{l}P \text { - } \\
\text { value }\end{array}$} \\
\hline & & Mean & SE & Mean & SE & \\
\hline \multicolumn{7}{|c|}{$\begin{array}{l}\text { Findings related to Model A show that the NDC significantly has better performance than MDC } \\
\text { regarding to husband's accompaniment, considering the mother's preferences about the type of } \\
\text { delivery, providing maternal and childcare information, the cleanliness of the delivery room from the } \\
\text { mother's point of view, providing answers to questions and concerns of mother, and postpartum } \\
\text { maternal health. However, mothers in NDC were significantly satisfied in terms of the amount of pain } \\
\text { experienced during labor and maternal follow up. There were no significant differences in other } \\
\text { dimensions of care quality. (Table 2) }\end{array}$} \\
\hline \multicolumn{7}{|c|}{$\begin{array}{l}\text { We present the results for the mothers who had experience of delivery in both centers in Table } 3 \text { as } \\
\text { Model B. The findings indicate the NDC is statistically had better performance than the MDC } \\
\text { regarding the experience of labor in a private room, husband's accompaniment, considering the } \\
\text { mother's preferences about the type of delivery, providing maternal and childcare information, } \\
\text { cleanliness and calmness in the delivery room, providing answers to questions and concerns of } \\
\text { mother and, the overall satisfaction of the mother with the delivery team. }\end{array}$} \\
\hline
\end{tabular}


Table 3

Quality of care from the mother's perspective whose gave birth in both the NDC and MDC in Iran (Model

B)

\begin{tabular}{|c|c|c|c|c|c|c|}
\hline \multirow[t]{2}{*}{ Quality of care variables } & \multirow{2}{*}{$\begin{array}{l}\text { Possible } \\
\text { ranges }\end{array}$} & \multicolumn{2}{|l|}{ NDC } & \multicolumn{2}{|l|}{ MDC } & \multirow{2}{*}{$\begin{array}{l}\mathrm{P} \text { - } \\
\text { value }\end{array}$} \\
\hline & & Mean & SE & Mean & SE & \\
\hline \multicolumn{7}{|l|}{ Structure factors } \\
\hline Privacy of delivery room & {$[0-100]$} & 100 & - & 0 & - & $<0.01$ \\
\hline Time to get the center (Minute) & {$[0-\infty)$} & 9.1 & 4.7 & 21.5 & 10.7 & 0.34 \\
\hline Waiting time (Minute) & {$[0-\infty)$} & 3.5 & 1.6 & 6.8 & 3.2 & 0.40 \\
\hline Cleanliness of delivery room & {$[1-5]$} & 4.95 & 0.78 & 3.22 & 0.18 & 0.02 \\
\hline Calmness of delivery room & {$[1-5]$} & 4.82 & 0.77 & 3.05 & 0.21 & 0.01 \\
\hline \multicolumn{7}{|l|}{ Process factors } \\
\hline Husband's Accompaniment & {$[0-100]$} & 67 & - & 9 & - & $<0.01$ \\
\hline $\begin{array}{l}\text { Taking into account mother's } \\
\text { preferences }\end{array}$ & [0-100] & 100 & - & 18 & - & $<0.01$ \\
\hline Reliable and intimate relationship & {$[1-5]$} & 4.81 & 0.63 & 3.28 & 0.51 & 0.06 \\
\hline Provide care information & {$[1-5]$} & 4.13 & 0.31 & 2.67 & 0.23 & $<0.01$ \\
\hline Meeting needs & {$[1-5]$} & 4.47 & 0.51 & 3.15 & 0.24 & 0.01 \\
\hline Answering questions & {$[1-5]$} & 4.73 & 0.71 & 2.73 & 0.15 & $<0.01$ \\
\hline Meeting concerns & {$[1-5]$} & 4.68 & 0.61 & 3.33 & 0.23 & 0.02 \\
\hline Provider skills & {$[1-5]$} & 4.73 & 0.51 & 3.98 & 0.37 & 0.22 \\
\hline \multicolumn{7}{|l|}{ Outcome factors } \\
\hline Pain & {$[1-5]$} & 4.58 & 0.68 & 4.79 & 0.77 & 0.84 \\
\hline Follow-up & {$[0-100]$} & 15 & - & 11 & - & 0.35 \\
\hline Maternal complications (\%) & {$[0-100]$} & 0 & - & 0 & - & 1 \\
\hline Newborn complication (\%) & {$[0-100]$} & 0 & - & 0 & - & 1 \\
\hline Mother's satisfaction & {$[1-5]$} & 4.88 & 0.78 & 3.26 & 0.27 & 0.03 \\
\hline \multicolumn{7}{|c|}{ Abbreviations: NDC, natural delivery center; MDC, Mixed delivery center; SE, standard error. } \\
\hline $\begin{array}{l}\text { Note: NDC is a delivery center whic } \\
\text { pregnancy. MDC is a delivery cente } \\
\text { the request of the mothers or to the }\end{array}$ & erform na & inal de & ery $f$ & ton-co & & \\
\hline
\end{tabular}




\section{Discussion}

This novel model for defining and assessing the quality of maternity care was used to compare the quality of maternity care provided by the NDC and MDC in Iran. The two groups of mothers did not have significant differences in demographic variables such as age, the income of households, educational level, occupation, and health insurance; however, their residence was statistically different. About $84 \%$ of mothers who gave birth in the NDC had lived in suburban, while this statistic for the MDC was $45 \%$.

To control the probable biases associated with differences in the pregnancy status of the studied groups, we choose only mothers without any unusual and complicating condition for delivery. Also, in the additional analysis, the quality of maternity care was compared only among mothers who had experience of giving birth in both centers. The questionnaire developed using Donabedian's health care quality model had a high level of reliability. Therefore, we can claim that these two groups were highly comparable, and the differences in the quality of maternity care can be attributed to the performance of the management and executive teams in the NDC and MDC.

\section{Structural factors}

The structural dimension of the quality of maternity care emphasizes the immediate and convenient access of pregnant women to safe facilities and trained human resources concerning the privacy of mother and baby. The findings of the study indicate that all mothers in the NDC, in contrast to the MDC, had private rooms that can promote the satisfaction level of mothers.[28, 29] In model B, mothers have stated that they have even experienced more silence and calmness in the NDC compared to the MDC, which may be due to the bias caused by the experience of delivery for a second time and more. In other words, it may be that mothers' perception of maternity is affected by the number of their births. Furthermore, in both models, mothers believed that the NDC was cleaner than MDC. Cleanliness can represent the health level of the delivery center, and according to the WHO definition, it has six dimensions that can significantly affect maternal and newborn health outcomes. These dimensions include a clean place; a clean surface; clean hands; perineum, clean cord and dressing; and a clean tie.[30] The mean access time to the MDC and NDC was 54.7 and 12.4 minutes, respectively. Although this difference was not statistically significant, it indicates poor accessibility to MDC and the acceptable condition for NDC. Given that these values in model B were 21.5 and 9.1 minutes, respectively, and MDC is a referral center, it can be inferred that both centers have appropriate geographical access. However, for referred cases, access to the MDC was not acceptable. Besides, the findings have shown that the average waiting time for admission is acceptable, although NDC has provided the maternity care services more quickly. According to Sanghita et al., structural factors such as quick access to delivery centers, the cleanliness of the environment, and the facilities play an essential role in the understanding of the mothers about the quality of services they receive.[31]

Process factors 
The process dimension covers all levels of contact between the mother and the provider of maternity services from the moment of admission to the moment of discharge. This dimension affects the satisfaction level of mothers and also determines the outcome of the model.[32] Increasing the process quality of maternal care during delivery will lower the mortality, unwanted complications, and maternal dissatisfaction.[33] Therefore, a high correlation between process and output dimensions is expected. Both models ( $A$ and $B$ ) confirmed that the husband's accompaniment, asking about delivery type preferences, and providing maternal and child-care information on behalf of the providers of maternity care at the NDC was much more prominent. However, the skills of gynecologists and midwives in normal vaginal delivery did not differ significantly from the perspective of mothers. Nevertheless, the mothers who have experienced delivery in both centers have suggested a more intimate relationship between them and midwives in comparison to the gynecologists, which increased the trust of mothers in the care team, and also the comfort of mothers before, during and after delivery. Process factors can significantly reduce the anxiety of mothers before, during, and after delivery,[34-36] strengthen maternal and infant health indicators, and increase maternal satisfaction with the health care provider.[37-39]

\section{Outcome factors}

The outcome dimension is the most crucial dimension of the quality of maternity care and addresses the objective and subjective outcomes of delivery. Measurable outcomes of delivery include maternal and neonatal mortality, morbidity, and follow-up rates. In this regard, the number of maternal and infant deaths and also the unwanted side effects of infants in both centers were not significantly different. However, in 6 cases and only in the MDC, complications such as a second degree perineal rupture after an episiotomy ( 1 case), persistent vaginal pain (3 cases), and dizziness ( 2 cases) were observed. All of these complications occurred in cases of normal vaginal delivery. However, to measure the mortality, morbidity, and unwanted complications of the mother and the infant, a time-series study or a longitudinal cohort study with a larger sample size should be conducted at the delivery centers to extract their actual rates.

Our cross-sectional study cannot accurately measure it for comparison and accurate judgment. Subjective maternal outcomes include the amount of pain experienced during labor and the degree to which the mother is satisfied with the overall performance of the delivery center. Findings indicate that the pain experienced by mothers at the NDC was much higher than the MDC, which could be due to this fact that $27 \%$ of delivery cases at the MDC were performed as cesarean section and also performing epidural anesthesia in MDC could affect the amount of pain felt by the mother. This hypothesis was confirmed by model $B$ since mothers that have experience in both centers did not report significant differences in experienced pain. However, this result could also be affected by childbirth experience and recall bias. The pain experienced in the first delivery may be more severe. Generally, the satisfaction of mothers from the NDC was higher than MDC, which is statistically significant in the model B. This finding is consistent with the findings of other studies that suggested that patients' satisfaction is a function of the quality of maternity care.[40,41] Overall, most of the results indicate that the quality of maternity care was higher in the NDC compared to the MDC. This difference in performance is due to the ability of the 
management team and providers, particularly midwives, in creating a better structure that led to quick, secure, high-quality, and reliable access to the delivery center.

\section{Limitations}

The findings of this study should be interpreted in light of the study limitations. First, this study did not cover the mothers with complicated and abnormal deliveries, such as premature delivery, prostrated and arrested labor, abnormal presentation, premature rupture of membranes, Umbilical Cord Prolapse, and so on. Therefore, the results of this study can be generalized only to mothers that have unproblematic deliveries where midwives can safely replace gynecologists. There is a strong likelihood that the results will change in favor of gynecologists by changing the sample. Secondly, since the findings of the study are influenced by four overall factors including the management and organization of delivery centers, the performance of the human resources, availability of resources and equipment, and the expectations of the mothers, the results cannot be attributed purely to the performance of midwives or gynecologists. However, only the process variables of the model can be attributed to the performance of healthcare providers. Midwives have shown better performance in comparison to gynecologists. This can be attributed to the friendly behavior of the midwives with the mothers, calmness of the NDC, and also lower occupational stress and workload of the midwives compared to the gynecologist. Thirdly, the crosssectional nature of the study did not allow us to ideally compare the two centers studied and also a comparison of midwives with gynecologists. The best alternative for this purpose is cohort studies that allow researchers to control the effects of temporal and behavioral variables. The strength of current research is in considering the cases who have had experience of delivery in both centers. However, recall bias may occur in their answers to their first experience at the MDC. Nevertheless, their statements and comparisons can be considered valid. Furthermore, this study presented a new, practical, and theorybased model for the quality of childbirth care that can be used by policymakers of any health system.

\section{Conclusion}

The maternity care model provided in this study is a practical, transparent, and theory-based model that can be used to measure, improve, and compare the quality of maternity care at various delivery centers. It can be a suitable tool for promoting maternal and child health indicators and also the satisfaction of mothers. Therefore, policymakers are recommended to evaluate the childbirth centers using this model and require them to follow it.

Also, as the findings of the study confirm, the policy of setting up natural childbirth centers run by trained midwives can have positive effects, including lowering cesarean rates, increasing the quality of maternity care, and reducing maternal and childcare costs. It is therefore strongly recommended that health systems use this successful experience to achieve the goals mentioned. As mentioned above, the performance of midwives in uncomplicated cases can be better than gynecologists. Therefore, more use of midwives, as a cost-effective force, in remote and less developed areas will be economically beneficial for health systems, because these forces are very cheap compared to gynecologists and they make lower 
costs for the health system. This strategy increases the level of access of the population to the mother and child services which significantly reduce inequity in access and utilization of these services, and improve health-related indicators. Therefore, as WHO has commissioned, the use of midwives could be the key to achieve national and international goals related to fertility, maternal, infant, and child health. [42] In conclusion, the NDC showed a higher quality of maternity care than the MDC, and also midwives had a higher quality of maternity care than obstetricians in the case of uncomplicated deliveries.

\section{Declarations}

\section{Acknowledgments}

We would like to thank Dr. Ali Sadeghianfar, head of Urmia health network, for data use authorization and his comments.

\section{Funding}

This research was supported by the Deputy of research and technology of Urmia University of Medical Sciences Grant Number 2273.

\section{Author information}

\section{Affiliations}

Department of Neurosurgery, Urmia University of Medical Sciences, Urmia, Iran

Reproductive Health Research Center, Urmia University of Medical Sciences, Urmia, Iran

Department of Biostatistics and Epidemiology, School of Medicine, Urmia University of

Medical Sciences, Urmia, Iran

Connective Tissue Diseases Research Center, Tabriz University of Medical Sciences, Tabriz, Iran Department of Occupational Health, Urmia University of Medical Sciences, Urmia, Iran

\section{Contributions}

JAA and IM conceived the idea of the study, IM and CA contributed to the study design, CA performed the statistical analysis, CA, IM, and REM took part in the interpretation of the results and JAA, MMAA, REM, 
and CA critically revised manuscript drafts. All authors read and approved the final version of the manuscript.

\section{Corresponding author}

Correspondence to Cyrus Alinia.

\section{Ethics declarations}

\section{Ethics approval and consent to participate}

This study protocol was reviewed by Research Ethics Committee at the Deputy of research and technology, Urmia University of Medical Sciences (No. IR.UMSU.REC.1396.451) and was found to comply with ethical standards.

\section{Consent for publication}

Not applicable.

\section{Competing interests}

The authors declare that they have no competing interes

\section{References}

1. Doctor HV, Nkhana-Salimu S, Abdulsalam-Anibilowo MJBph: Health facility delivery in sub-Saharan Africa: successes, challenges, and implications for the 2030 development agenda. 2018, 18(1):765.

2. Saleem S, McClure EM, Goudar SS, Patel A, Esamai F, Garces A, Chomba E, Althabe F, Moore J, Kodkany BJBotWHO: A prospective study of maternal, fetal and neonatal deaths in low-and middleincome countries. 2014, 92:605-612.

3. Tolera M, Teklu AM, Ahmed A, Hashi A, Oljira L, Abebe Z, Gezahegn W, Kidan KGJJomcr: Use of a qualitative case study to learn lessons from severe preeclampsia causing a maternal near-miss: a case report. 2018, 12(1):277.

4. Munshi V, Yamey G, Verguet SJHA: Trends in state-level child mortality, maternal mortality, and fertility rates in India. 2016, 35(10):1759-1763.

5. Okwaraji YB, Webb EL, Edmond KMJBhsr: Barriers in physical access to maternal health services in rural Ethiopia. 2015, 15(1):493.

6. Assembly GJS, Transforming our world: the: sustainable Development goals. 2015, 2030. 
7. Roos N, von Xylander SRJBP, Obstetrics RC, Gynaecology: Why do maternal and newborn deaths continue to occur? 2016, 36:30-44.

8. Bowen RMJFC, SDGs t: Reduce Maternal and Infant Mortality. 2016:60.

9. Biro MA: What has public health got to do with midwifery? Midwives' role in securing better health outcomes for mothers and babies. Women and birth : journal of the Australian College of Midwives 2011, 24(1):17-23.

10. Starrs AMJTL: Safe motherhood initiative: 20 years and counting. 2006, 368(9542):1130-1132.

11. Keyes EB, Haile-Mariam A, Belayneh NT, Gobezie WA, Pearson L, Abdullah M, Kebede HJIJoG, Obstetrics: Ethiopia's assessment of emergency obstetric and newborn care: Setting the gold standard for national facility-based assessments. 2011, 115(1):94-100.

12. Penn-Kekana L, Pereira S, Hussein J, Bontogon H, Chersich M, Munjanja S, Portela AJBp, childbirth: Understanding the implementation of maternity waiting homes in low-and middle-income countries: a qualitative thematic synthesis. 2017, 17(1):269.

13. Bahadoran P, Alizadeh S, Valiani MJ: xploring the Role of Midwives in Health Care System in Iran and the World. 2009, 14(3).

14. Anahita E, Ameneh S-R: Midwifery in Iran. In: Starting Life as a Midwife. edn.: Springer; 2019: 131140.

15. Alianmoghaddam N: The importance of Midwife Runs Primary Units in Iran \% J Journal of Clinical Care and Skills. 2019, 1(1):1-3.

16. Wiegers TAJBp, childbirth: The quality of maternity care services as experienced by women in the Netherlands. 2009, 9(1):18.

17. Yazdizadeh B, Nedjat S, Mohammad K, Rashidian A, Changizi N, Majdzadeh R: Cesarean section rate in Iran, multidimensional approaches for behavioral change of providers: a qualitative study. $B M C$ health services research 2011, 11:159.

18. World Health Organization: Appropriate technology for birth. Lancet (London, England) 1985, 2(8452):436-437.

19. Molina G, Weiser TG, Lipsitz SR, Esquivel MM, Uribe-Leitz T, Azad T, Shah N, Semrau K, Berry WR, Gawande AA et al: Relationship Between Cesarean Delivery Rate and Maternal and Neonatal Mortality. Jama 2015, 314(21):2263-2270.

20. Lumbiganon P, Laopaiboon M, Gulmezoglu AM, Souza JP, Taneepanichskul S, Ruyan P, Attygalle DE, Shrestha N, Mori R, Nguyen DH et al: Method of delivery and pregnancy outcomes in Asia: the WHO global survey on maternal and perinatal health 2007-08. Lancet (London, England) 2010, 375(9713):490-499.

21. Villar J, Valladares E, Wojdyla D, Zavaleta N, Carroli G, Velazco A, Shah A, Campodonico L, Bataglia V, Faundes A et al: Caesarean delivery rates and pregnancy outcomes: the 2005 WHO global survey on maternal and perinatal health in Latin America. Lancet (London, England) 2006, 367(9525):18191829. 
22. Redshaw MJB: Women as consumers of maternity care: measuring "satisfaction" or "dissatisfaction"? 2008, 35(1):73-76.

23. Donabedian A: The quality of care. How can it be assessed? Jama 1988, 260(12):1743-1748.

24. Wiegers TA: The quality of maternity care services as experienced by women in the Netherlands. BMC pregnancy and childbirth 2009, 9:18.

25. Carter MC, Corry M, Delbanco S, Foster TC, Friedland R, Gabel R, Gipson T, Jolivet RR, Main E, Sakala $C$ et al: $\mathbf{2 0 2 0}$ vision for a high-quality, high-value maternity care system. Women's health issues : official publication of the Jacobs Institute of Women's Health 2010, 20(1 Suppl):S7-17.

26. Proctor $S$ : What determines quality in maternity care? Comparing the perceptions of childbearing women and midwives. Birth (Berkeley, Calif) 1998, 25(2):85-93.

27. Roberts CL, Bell JC, Ford JB, Morris JM: Monitoring the quality of maternity care: how well are labour and delivery events reported in population health data? Paediatric and perinatal epidemiology 2009, 23(2):144-152.

28. Janssen PA, Klein MC, Harris SJ, Soolsma J, Seymour LC: Single room maternity care and client satisfaction. Birth (Berkeley, Calif) 2000, 27(4):235-243.

29. Maben J, Griffiths P, Penfold C, Simon M, Anderson JE, Robert G, Pizzo E, Hughes J, Murrells T, Barlow J: One size fits all? Mixed methods evaluation of the impact of $100 \%$ single-room accommodation on staff and patient experience, safety and costs. BMJ quality \& safety 2016, 25(4):241-256.

30. Organization WH: Essential newborn care: report of a technical working group (Trieste, 25-29 April 1994). 1994.

31. Bhattacharyya S, Srivastava A, Avan BI: Delivery should happen soon and my pain will be reduced: understanding women's perception of good delivery care in India. Global health action 2013, 6:22635.

32. Cleary PD, McNeil BJ: Patient satisfaction as an indicator of quality care. Inquiry : a journal of medical care organization, provision and financing 1988, 25(1):25-36.

33. Berwick D, Fox DMJTMQ: “Evaluating the quality of medical care”: Donabedian's classic article 50 years later. 2016, 94(2):237.

34. Salehi A, Fahami F, Beigi MJljon, research m: The effect of presence of trained husbands beside their wives during childbirth on women's anxiety. 2016, 21(6):611.

35. Attarha M, Keshavarz Z, Bakhtiari M, Jamilian MJH: The outcome of midwife-mother relationship in delivery room: A qualitative content analysis. 2016, 8(04):336.

36. Reed R, Sharman R, Inglis CJBp, childbirth: Women's descriptions of childbirth trauma relating to care provider actions and interactions. 2017, 17(1):21.

37. Srivastava A, Avan BI, Rajbangshi P, Bhattacharyya SJBp, childbirth: Determinants of women's satisfaction with maternal health care: a review of literature from developing countries. 2015, 15(1):97. 
38. Creanga AA, Gullo S, Kuhlmann AKS, Msiska TW, Galavotti CJBp, childbirth: Is quality of care a key predictor of perinatal health care utilization and patient satisfaction in Malawi? 2017, 17(1):150.

39. Atiya KMJIJoN, Midwifery: Maternal satisfaction regarding quality of nursing care during labor and delivery in Sulaimani teaching hospital. 2016, 8(3):18-27.

40. Sharma G, Mathai M, Dickson KE, Weeks A, Hofmeyr GJ, Lavender T, Day LT, Mathews JE, Fawcus S, Simen-Kapeu AJBp et al: Quality care during labour and birth: a multi-country analysis of health system bottlenecks and potential solutions. 2015, 15(2):S2.

41. Organization WH: WHO recommendations on antenatal care for a positive pregnancy experience: World Health Organization; 2016.

42. ten Hoope-Bender P, de Bernis L, Campbell J, Downe S, Fauveau V, Fogstad H, Homer CS, Kennedy HP, Matthews Z, McFadden AJTL: Improvement of maternal and newborn health through midwifery. 2014, 384(9949):1226-1235. 